\title{
Aspectos toxinológicos e inmunoquímicos del veneno del escorpión Tityus pachyurus Pocock de Colombia: capacidad neutralizante de antivenenos producidos en Latinoamérica
}

\author{
Jacqueline Barona, Rafael Otero, Vitelbina Núñez
}

Programa de Ofidismo/Escorpionismo, Facultad de Medicina, Universidad de Antioquia, Medellín, Colombia.

Este trabajo se realizó con el objetivo de determinar la toxicidad y las características inmunoquímicas del veneno del escorpión Tityus pachyurus y su neutralización por tres antivenenos antiescorpión producidos en Latinoamérica: Alacramyn ${ }^{\circledR}$ del Instituto Bioclón de México; el suero antiescorpiónico del Instituto Butantán de São Paulo, Brasil, y el suero antiescorpiónico del Centro de Biotecnología de la Universidad Central de Venezuela, Caracas, Venezuela. Este escorpión produjo $0,68 \pm 0,20 \mathrm{mg}$ (promedio $\pm \mathrm{DE}$ ) de veneno por estimulación manual, el cual presentó una dosis letal 50\% $\left(\mathrm{DL}_{50}\right)$ en ratones de 4,8 $\mu \mathrm{g} / \mathrm{kg}(91,3 \mu \mathrm{g} / \mathrm{ratón}$ de 18-20 g). Los signos de envenenamiento predominantes en los ratones fueron: sialorrea, dificultad respiratoria, sudoración generalizada, ataxia, alteraciones del comportamiento (excitabilidad, somnolencia) e hiperglicemia 3 y 24 horas después de la inyección $0,5 \mathrm{DL}_{50}$ del veneno por vía subcutánea. Para los antivenenos de México y Brasil, la dosis efectiva $50 \%$ neutralizante del efecto letal fue de 330 y $292 \mu \mathrm{g}$ de veneno por $\mathrm{ml}$ de antiveneno, respectivamente. El antiveneno de Venezuela no neutralizó este efecto. Por electroforesis (SDS-PAGE) se demostró que el veneno contiene proteínas desde menos de 14 kd hasta 97 kd. Los Western blot indicaron reactividad inmunológica de los tres antivenenos con los diversos componentes del veneno, incluso las proteínas de baja masa molecular $(<14 \mathrm{kd})$. Los resultados permiten concluir que el veneno de T. pachyurus es neutralizado eficientemente por los antivenenos contra picaduras de escorpiones producidos en México y Brasil.

Palabras clave: escorpión, veneno, antiveneno, Tityus pachyurus, Colombia.

Toxicological and immunological aspects of scorpion venom (Tytius pachyurus): neutralizing capacity of antivenoms produced in Latin America

The toxicity and immunochemical properties of Tityus pachyurus Pocock scorpion venom was characterized, as well as the neutralization capacity against it by three anti-scorpion antivenoms (Alacramyn $^{\circledR}$, Instituto Bioclón, México; Suero antiescorpiónico, Instituto Butantán, Sao Paulo, Brasil; and Suero antiescorpiónico, Centro de Biotecnología, Universidad Central de Venezuela, Caracas, Venezuela). The venom yield, obtained by manual milking, $680 \pm 20 \mu \mathrm{g}$ venom, a $50 \%$ lethal dose in mice was $4.8 \mu \mathrm{g} / \mathrm{kg}$ (90 $\mu \mathrm{g}$ for an $18-20 \mathrm{~g}$ mouse). The most common symptoms of venom poisoning in mice were sialorrhea, respiratory distress, profuse sweating, ataxia, behavior alterations (restlessness, somnolence) and hyperglycemia at 3 and 24 hours after subcutaneous venom injection $\left(0.5 \mathrm{LD}_{50}\right)$. The neutralizing capacity of Bioclón (México City) and Butantán (Sao Paulo) antivenoms (for a 50\% effective dose) was 330 and $292 \mu \mathrm{g}$ venom $/ \mathrm{ml}$ antivenom, respectively. The Biotecnología (Caracas) antivenom did not neutralize the lethal effect of venom. By electrophoresis (SDS-PAGE) was demonstrated that the venom contains proteins from less than $14 \mathrm{kd}$ to $97 \mathrm{kd}$. The Western blots indicated immunological reactivity of the three antivenoms with most of venom components, including proteins of low molecular mass $(<14 \mathrm{kd})$. The results allow to conclude that $T$. pachyurus venom is neutralized efficiently by anti-scorpion antivenoms produced in México and Brasil.

Key words: scorpion, venom, antivenom, Tityus pachyurus, Colombia. 
Hasta la fecha, se han descrito en el mundo cerca de 1.500 especies de escorpiones ubicadas en 21 familias (1). La familia Buthidae, que constituye la familia de interés médico, está representada en Colombia por cuatro géneros: Ananteris, Centruroides, Tityus y Rhopalurus, con 35 especies, de las cuales, 29 pertenecen al género Tityus (2-7).

En Latinoamérica, los países más afectados por el escorpionismo son México y Brasil con 200.000 y 8.000 casos al año, respectivamente $(8,9)$. Las especies de escorpiones más importantes son Centruroides spp. en México y Tityus serrulatus en Brasil (10). Los efectos neurotóxicos colinérgicos y adrenérgicos de los venenos de escorpiones se han caracterizado en humanos y en animales de experimentación, así como la capacidad neutralizante de los antivenenos específicos y la existencia de reactividad cruzada con los venenos de otras especies de la familia Buthidae que no se utilizaron en la mezcla inmunizante (8,11-16).

En Colombia no se producen antivenenos contra picaduras de escorpión y las publicaciones sobre los aspectos clínicos, epidemiológicos y toxinológicos del escorpionismo aún son escasas en el país, con carencia de estudios epidemiológicos prospectivos (2,17-19). Sin embargo, la existencia de accidentes escorpiónicos graves y de casos fatales en niños de Antioquia y Tolima, descrita por Otero y colaboradores (17), motivó la realización de un estudio prospectivo clínicoepidemiológico (2000-2001) en 5 municipios de Tolima y 10 de Antioquia. La incidencia del accidente escorpiónico fue significativamente mayor en Tolima (12,4 casos/100.000 hab/año) que en Antioquia ( 2,3 casos/100.000 hab/año). En el primero, el $64,1 \%$ de los accidentes fueron ocasionados por Tityus pachyurus Pocock (1897), principalmente en Ibagué, Flandes, Espinal y Melgar; el 25,6\% fue por Centruroides gracilis,

\footnotetext{
Correspondencia:

Jacqueline Barona, Programa de Ofidismo/Escorpionismo, Facultad de Medicina, Universidad de Antioquia, apartado aéreo 1226, Medellín, Colombia.

Telefax: (57-4) 2631914

jacqbar@yahoo.com
}

Recibido: 28/08/04; aceptado: 13/02/04 especie particularmente frecuente en el municipio de Ortega (20).

A partir de este hallazgo y teniendo en cuenta el desconocimiento de las características toxinológicas e inmunoquímicas de los venenos de escorpiones colombianos, se diseñó un estudio para determinar estos aspectos en el veneno de T. pachyurus (dosis letal $50 \%$, signos clínicos y alteraciones metabólicas del envenenamiento experimental en ratones) y, además, para evaluar la capacidad neutralizante frente al efecto letal del veneno (dosis efectiva $50 \%$ ) de tres antivenenos latinoamericanos producidos en otros países y la reactividad inmunológica mediante Western blotting.

\section{Materiales y métodos}

\section{Animales y veneno}

Se incluyeron en el estudio 31 escorpiones adultos de T. pachyurus de 6 a $9 \mathrm{~cm}$ (figura 1) procedentes del departamento de Tolima (Ibagué, Melgar y Espinal), los cuales fueron mantenidos en el Escorpionario de la Universidad de Antioquia en cajas plásticas, con tierra como sustrato, un recipiente pequeño con agua y un trozo de madera que les permitiera ocultarse. Se alimentaron cada quince días con larvas de coleóptero (Tenebrios) y cucarachas adultas (Periplaneta americana).

Para las pruebas de toxicidad, se utilizaron ratones cepa Swiss Webster con un peso de 18 a $20 \mathrm{~g}$. El veneno se extrajo por estimulación física del telson (2), con intervalos de 30 días (tres extracciones por cada ejemplar); luego, se disolvió en agua desionizada y se hizo una mezcla que se centrifugó a $15.000 \mathrm{~g}$ por 30 minutos a $12^{\circ} \mathrm{C}$. El sobrenadante se liofilizó y se guardó congelado a $-70{ }^{\circ} \mathrm{C}$ hasta su uso.

\section{Antivenenos}

Se utilizaron tres antivenenos $F\left(a b^{\prime}\right)_{2}$ producidos en Latinoamérica: 1) el antiveneno polivalente Alacramyn ${ }^{\circledR}$, lote B-1 B-03, de presentación liofilizada para reconstituirse en $5 \mathrm{ml}$, con fecha de caducidad del 20 de febrero de 2005, producido en el Instituto Bioclón de México por inmunización de caballos con los venenos de Centruroides limpidus limpidus, Centruroides noxius noxius, Centruroides limpidus tecomanus y Centruroides 


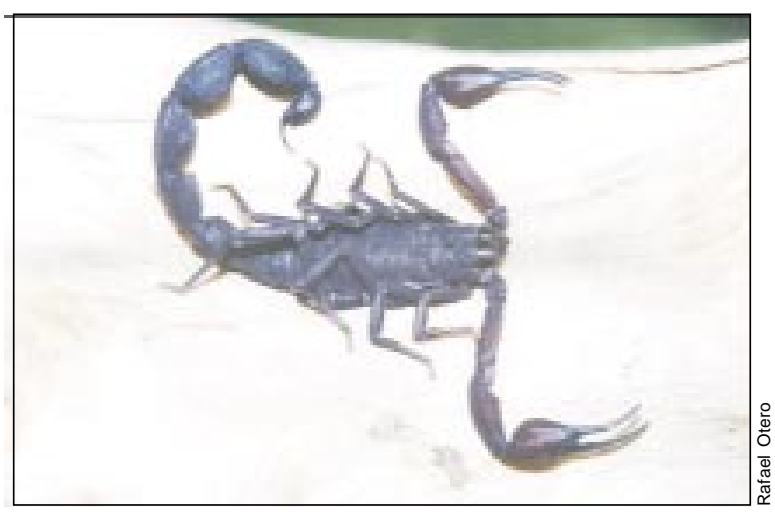

Figura 1. Tityus pachyurus, macho adulto. Obsérvese la coloración rojiza de los pedipalpos y los dos últimos segmentos $\left(4^{\circ}\right.$ y $\left.5^{\circ}\right)$ del posabdomen o metasoma más gruesos y más oscuros.

sufusus sufusus; 2) el suero antiescorpiónico del Instituto Butantán de São Paulo, Brasil, lote 0003035/C, en presentación líquida de $5 \mathrm{ml}$, con fecha de caducidad del 2 de febrero de 2003, preparado contra los venenos de Tityus serrulatus y Tityus bahiensis, y 3) el suero antiescorpión del Centro de Biotecnología de la Facultad de Farmacia de la Universidad Central de Venezuela, lote 028, en presentación líquida de $5 \mathrm{ml}$, con fecha de caducidad de junio de 2002, producido contra el veneno de Tityus discrepans de la zona centronorte de Venezuela.

\section{Aspectos toxinológicos}

La dosis letal $50 \%\left(\mathrm{DL}_{50}\right)$ para los ratones inoculados se determinó por medio del método de Spearman Karber (18). Para ello, se inocularon intraperitonealmente dosis variables de veneno diluido en $500 \mu \mathrm{l}$ de solución salina en amortiguador de fosfatos (PBS), $\mathrm{pH} 7,2$, a grupos de cuatro ratones por dosis. La mortalidad se registró durante 48 horas.

Para identificar los signos de envenenamiento sistémico (sialorrea, taquipnea, hiperhidrosis, etc.), se inocularon dos grupos de 10 ratones: el grupo 1 por vía subcutánea en la almohadilla plantar derecha con $1 \mathrm{DL}_{50}$ del veneno diluido en $50 \mu$ de PBS y el grupo 2 por vía intraperitoneal con $1 \mathrm{DL}_{50}$ del veneno diluido en $500 \mu \mathrm{l}$ de PBS. Los ratones se observaron durante 24 horas a los 15,30 y 60 minutos y a las 3 y 24 horas. También, se determinaron las $\alpha$-amilasas (U/L) (21), la glucosa (mg/dl) (22) y el calcio sérico (mg/dl) (23) a los 30 y 60 minutos, 3 y 24 horas, con los reactivos de Spinreact, S.A., Ctra. Santa Coloma, Girona (España), en grupos de 10 ratones inoculados por vía subcutánea con $0,5 \circ 1 \mathrm{DL}_{50}$. Se incluyeron grupos controles inoculados con PBS.

\section{Aspectos inmunoquímicos}

La concentración de proteínas del veneno se determinó por el método de Bradford modificado por Spector, con albúmina sérica bovina como estándar (24).

Para el análisis electroforético del veneno, se corrieron $50 \mu \mathrm{g}$ del veneno total liofilizado, equivalentes a 7,6 $\mu \mathrm{g}$ de proteína, en geles de poliacrilamida (SDS-PAGE) al $15 \%$ en condiciones no reducidas (25). Para ello, se utilizó una cámara Mini-Protean II de Bio-Rad (Richmond, CA, USA). Al terminar la corrida electroforética de 60 minutos, las proteínas se detectaron con el colorante Coomassie Blue R-250. Paralelamente, se corrió un marcador de masa molecular $(14,26)$.

Para el Western blotting, el veneno crudo separado por SDS-PAGE, como se describió anteriormente, se transfirió a membranas de nitrocelulosa durante 90 min en una cámara Mini-Transblot ${ }^{\circledR}$ de BioRad. Las membranas se incubaron, luego, con los antivenenos descritos en una dilución de 1:250 durante toda la noche a temperatura ambiente. Se empleó como segundo anticuerpo $\operatorname{lgG}$ de conejo anti-lgG equina conjugada con peroxidasa en una dilución de 1:1000, incubado dos horas a temperatura ambiente y 4-Cl-1-naftol como sustrato (27).

\section{Neutralización de la letalidad}

Estos experimentos se realizaron con preincubación de veneno y antiveneno, antes de la fecha de caducidad de los tres productos. Se incubaron dosis variables de antiveneno y una dosis fija de veneno $\left(1,5 \mathrm{DL}_{50}\right)$ a $37^{\circ} \mathrm{C}$ durante 30 minutos. Estas mezclas se inocularon, luego, por vía intraperitoneal a grupos de 4 ratones por cada dosis y se registró el número de sobrevivientes en 48 horas de observación. La dosis efectiva $50 \%$ $\left(D_{50}\right)$, definida como la dosis que protege de la 
muerte al $50 \%$ de la población de ratones y expresada en microgramos de veneno que son neutralizados por $1 \mathrm{ml}$ de antiveneno, se obtuvo mediante el método de Spearman-Karber $(28,29)$. Se hallaron también la dosis efectiva $100 \%\left(D_{100}\right)$ y los tiempos de supervivencia con diferentes dosis y antivenenos, al compararlos con el grupo control que recibió solamente veneno.

\section{Análisis estadístico}

Los datos de las cuantificaciones séricas se analizaron por medio de las pruebas estadísticas de Anova y el método de Dunnett para comparar diferencias estadísticamente significativas con el control. Se utilizó el paquete estadístico Statistica 98. Los resultados se expresaron como la media $\pm D E$. Las diferencias se consideraron estadísticamente significativas cuando $\alpha=0,05$.

\section{Resultados}

\section{Aspectos toxinológicos}

T. pachyurus produjo $0,68 \pm 0,20 \mathrm{mg}$ de veneno por estimulación física del telson ( $n=31$ especímenes, promedio $\pm \mathrm{DE}$ de tres extracciones por cada ejemplar) con límites de 0,3 y 1,0 mg veneno/ especimen/extracción. La $\mathrm{DL}_{50}$ por vía intraperitoneal en ratones fue de $4,8 \mu \mathrm{g} / \mathrm{kg}(91,3 \mathrm{mg} /$ ratón de 18 a $20 \mathrm{~g}$ ), con límites de confianza del $95 \%$ de 4,4 a $5,2 \mathrm{mg} / \mathrm{kg}$. La dosis letal $100 \%$ $\left(\mathrm{DL}_{100}\right)$, definida como la dosis de veneno que ocasionó la muerte al $100 \%$ de los ratones inoculados, fue de $5,3 \mathrm{mg} / \mathrm{kg}(100,4 \mu \mathrm{g} /$ ratón de 18 a $20 \mathrm{~g}$ ).

Después de la inoculación del veneno por vía subcutánea, los signos tóxicos predominantes fueron: sialorrea, dificultad respiratoria, sudoración generalizada, marcha errática (ataxia) y alteraciones del comportamiento (excitabilidad, somnolencia) en los primeros 15-30 minutos posteriores a la inoculación. Estos signos se observaron con mayor frecuencia cuando se usó la vía intraperitoneal, además de hiperhidrosis, lagrimación y muerte, sólo por esta vía (cuadro 1). La muerte ocurrió en las primeras 3 horas. Hubo diferencias significativas con respecto al grupo control en los niveles de glucosa (hiperglicemia; $p<0,001) 3$ y 24 horas después de la inyección de $0,5 \mathrm{DL}_{50}$ del veneno por vía subcutánea (cuadro 2), pero no con la inyección de $1 \mathrm{DL}_{50}$ subcutáneamente. Tampoco se observaron alteraciones en las concentraciones de $\alpha$-amilasas y calcio séricos con ninguna de las dosis ensayadas (datos no mostrados).

\section{Aspectos inmunoquímicos}

El veneno tuvo una concentración de proteínas de $0,153 \mathrm{mg} / \mathrm{ml}$ (promedio de tres determinaciones). Se demostró por electroforesis (SDSPAGE) que contiene proteínas desde menos de 14 kd hasta 97 kd (figura 2A). Se observó por

Cuadro 1. Signos de envenenamiento experimental en ratones."

\begin{tabular}{|c|c|c|c|c|c|c|c|c|c|c|}
\hline \multirow{3}{*}{$\begin{array}{l}\text { Signos de } \\
\text { envenenamiento }\end{array}$} & \multicolumn{8}{|c|}{ Frecuencias relativas } & \multirow{2}{*}{\multicolumn{2}{|c|}{$24 \mathrm{~h}$}} \\
\hline & \multicolumn{2}{|c|}{$15 \min$} & \multicolumn{2}{|c|}{$30 \mathrm{~min}$} & \multicolumn{2}{|c|}{$60 \mathrm{~min}$} & \multicolumn{2}{|c|}{$3 \mathbf{h}$} & & \\
\hline & sc & ip & sc & ip & sc & ip & sc & ip & sc & ip \\
\hline Sialorrea & $7 / 10$ & $6 / 10$ & $10 / 10$ & $10 / 10$ & $0 / 10$ & $8 / 8$ & $0 / 10$ & $0 / 4$ & $0 / 10$ & $0 / 4$ \\
\hline Hiperhidrosis & $0 / 10$ & $3 / 10$ & $0 / 10$ & $10 / 10$ & $0 / 10$ & $4 / 8$ & $0 / 10$ & $0 / 4$ & $0 / 10$ & $0 / 4$ \\
\hline Dificultad respiratoria & $9 / 10$ & $10 / 10$ & $10 / 10$ & $10 / 10$ & $10 / 10$ & $8 / 8$ & $6 / 10$ & $4 / 4$ & $1 / 10$ & $0 / 4$ \\
\hline Excitabilidad & $9 / 10$ & $0 / 10$ & $5 / 10$ & $10 / 10$ & $0 / 10$ & $0 / 8$ & $0 / 10$ & $0 / 4$ & $0 / 10$ & $0 / 4$ \\
\hline Somnolencia & $0 / 10$ & $1 / 10$ & $0 / 10$ & $0 / 10$ & $10 / 10$ & $4 / 8$ & $3 / 10$ & $2 / 4$ & $0 / 10$ & $0 / 4$ \\
\hline Lagrimación & $0 / 10$ & $4 / 10$ & $0 / 10$ & $10 / 10$ & $0 / 10$ & $0 / 8$ & $0 / 10$ & $0 / 4$ & $0 / 10$ & $0 / 4$ \\
\hline Ondulaciones de cola & $5 / 10$ & $1 / 10$ & $2 / 10$ & $2 / 10$ & $0 / 10$ & $0 / 8$ & $0 / 10$ & $0 / 4$ & $0 / 10$ & $0 / 4$ \\
\hline Ataxia (marcha errática) & $0 / 10$ & $2 / 10$ & $4 / 10$ & $3 / 10$ & $0 / 10$ & $4 / 8$ & $0 / 10$ & $0 / 4$ & $0 / 10$ & $0 / 4$ \\
\hline Convulsiones & $0 / 10$ & $0 / 10$ & $0 / 10$ & $0 / 10$ & $0 / 10$ & $1 / 8$ & $0 / 10$ & $0 / 4$ & $0 / 10$ & $0 / 4$ \\
\hline Muerte & $0 / 10$ & $0 / 10$ & $0 / 10$ & $0 / 10$ & $0 / 10$ & $2 / 10$ & $0 / 10$ & $4 / 8$ & $0 / 10$ & $0 / 4$ \\
\hline
\end{tabular}

" Se inocularon dos grupos de 10 ratones por vía subcutánea (sc) (grupo 1) con $1 \mathrm{DL}_{50}$ del veneno de T. pachyurus diluida en $50 \mu \mathrm{l}$ de PBS, o por vía intraperitoneal (ip) (grupo 2) con $1 \mathrm{DL}_{50}$ diluida en $0,5 \mathrm{ml}$ de PBS. Los ratones se observaron a los 15,30 y 60 minutos, y a las 3 y 24 horas. Los datos indican la razón del número de ratones en los cuales se observó el signo de envenenamiento y el número de ratones sobrevivientes en ese mismo intervalo de tiempo en cada grupo. 
Cuadro 2. Niveles de glucosa sérica en ratones inoculados con veneno de Tityus pachyurus ?.

\begin{tabular}{|c|c|c|}
\hline Tiempo & $\begin{array}{c}\text { Niveles de } \\
\text { (mg/dl) según } \\
0,5 \mathrm{DL}_{50}\end{array}$ & $\begin{array}{l}\text { sa sérica } \\
\text { de veneno } 19 \pi \\
1 \mathrm{DL}_{50}\end{array}$ \\
\hline 30 minutos & $150 \pm 14$ & $115 \pm 48$ \\
\hline 60 minutos & $115 \pm 15$ & $95 \pm 42$ \\
\hline 3 horas & $183 \pm 18$ * & $133 \pm 38$ \\
\hline 24 horas & $160 \pm 13^{*}$ & $132 \pm 34$ \\
\hline
\end{tabular}

त Resultados expresados como la media $\pm \mathrm{DE}$; grupo control negativo $=130 \pm 24 \mathrm{mg} / \mathrm{dl}$.

7i Se inocularon grupos de 10 ratones $(18-20 \mathrm{~g})$ por vía subcutánea con la dosis respectiva de veneno diluida en $50 \mu$ de PBS, $\mathrm{pH} 7,2$.

* Diferencia estadísticamente significativa con el contro según la prueba de Anova y de Dunnett $(F=11,5 ; p<0,001)$

Western blot reactividad inmunológica de los tres antivenenos con los diversos componentes del veneno, incluyendo las proteínas de masa molecular $<14$ kd (figura 2B).

\section{Neutralización de la letalidad}

Los antivenenos de México y Brasil neutralizaron eficientemente el efecto letal del veneno de $T$. pachyurus.

La $\mathrm{DE}_{50}$ para el antiveneno Alacramyn ${ }^{\circledR}$ de México fue de $330 \mu \mathrm{g}$ de veneno $/ \mathrm{ml}$ de antiveneno, con límites de confianza del $95 \%$ de 260 a $410 \mu \mathrm{g} / \mathrm{ml}$. Para el antiveneno de Brasil, fue de $292 \mu \mathrm{g}$ de veneno/ml de antiveneno, con límites de confianza

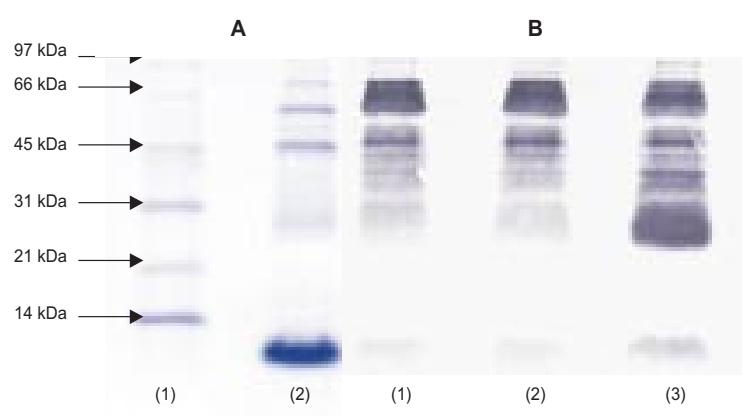

Figura 2. A) SDS-PAGE en condiciones no reductoras, gel al $15 \%$, con $50 \mu \mathrm{g}$ de veneno total liofilizado $(7,6 \mu \mathrm{g}$ de proteína): 1) marcador de masa molecular; 2) veneno total. B) Reactividad por Western blot: 1) del antiveneneno Alacramyn ${ }^{\circledR}$ (México); 2) del suero antiescorpiónico de la Universidad Central de Venezuela; 3) del suero antiescorpiónico del Instituto Butantán (Brasil) contra el veneno total de T. pachyurus. del $95 \%$ de 230 a $370 \mu \mathrm{g} / \mathrm{ml}$. La $\mathrm{DE}_{100}$ para los mismos antivenenos fue de $225 \mu \mathrm{g}$ de veneno $/ \mathrm{ml}$ de antiveneno, es decir, que para neutralizar 1,0 $\mathrm{mg}$ de veneno se requieren $4,4 \mathrm{ml}$ de antiveneno (aproximadamente, una ampolla de $5 \mathrm{ml}$ ). No se pudo determinar la $D_{50}$ del antiveneno de Venezuela por su baja potencia. Sin embargo, éste aumentó el tiempo de supervivencia de los ratones ( $75 \mathrm{~min}$ ) al compararlo con el grupo control ( $\leq 60 \mathrm{~min})$ que recibió sólo veneno $\left(1,5 \mathrm{DL}_{50}\right.$ intraperitoneal=137 $\mu \mathrm{g} / \mathrm{ratón}$ de $18-20 \mathrm{~g}$ de peso).

\section{Discusión}

Los escorpiones viven en regiones áridas o húmedas tropicales y subtropicales del mundo $(2,10,11)$. T. pachyurus Pocock (1897) (figura 1) se caracteriza por presentar los pedipalpos rojizos y los dos últimos segmentos ( $4^{\circ}$ y $5^{\circ}$ ) del posabdomen o metasoma más gruesos y más oscuros. Su tamaño oscila entre los 60 y los 120 $\mathrm{mm}$ de longitud y es de hábitos intra y extradomiciliarios $(20,30)$. Se encuentra distribuido entre los 100 y los $1.300 \mathrm{~m}$ de altitud, en los departamentos de Boyacá, Caldas, Cundinamarca, Huila, Antioquia y Tolima, principalmente en el valle del medio y alto Magdalena $(3,20,30)$. Morfológicamente, Lourenço lo ubica en el grupo $T$. asthenes, al cual pertenecen escorpiones grandes de 65 a $150 \mathrm{~mm}$, pigmentación negruzca en el estado adulto y amarillenta variable en individuos inmaduros, subacúleo espinoide, granulaciones espinoides en los segmentos metasomales II a IV y lámina basal intermedia de los peines de las hembras dilatada en casi todas las especies $(5,6)$.

El veneno de los escorpiones está compuesto principalmente por proteínas básicas de baja masa molecular (neurotoxinas) que se han aislado e identificado por cromatografía, electroforesis y ensayos de competición (8). Éstas actúan sobre canales iónicos dependientes del voltaje (principalmente, $\mathrm{Na}^{+}, \mathrm{Ca}^{++}, \mathrm{K}^{+}$y Cl-) en membranas excitables (tejido nervioso, glandular y muscular); modifica su permeabilidad iónica, las despolariza y produce liberación de neurotransmisores en las terminaciones posganglionares del simpático y del parasimpático. El cuadro clínico del envenenamiento depende de la predominancia de los 
efectos adrenérgicos o colinérgicos, o de la combinación de ambos $(17,31,32)$.

La producción promedio de veneno para $T$. pachyurus fue muy similar a la descrita para otras especies de escorpiones del grupo $T$. asthenes como T. fuhrmannide Colombia (33). Su DL ${ }_{50}(4,8$ $\mathrm{mg} / \mathrm{kg}$ ) permite clasificarlo como moderadamente tóxico al compararlo con venenos de escorpiones de la misma familia de alta toxicidad como $C$. noxius de México $(0,26 \mathrm{mg} / \mathrm{kg})$ y Tityus serrulatus de Brasil (1,2 mg/kg), y de baja toxicidad como $T$. cambridgeide Brasil $(12 \mathrm{mg} / \mathrm{kg})(8,14)$. Los signos de envenenamiento observados en los ratones, coinciden con los efectos inducidos por venenos de otros escorpiones de la familia Buthidae tanto en animales de experimentación como en seres humanos $(8,13,30,33,34)$.

El veneno es de rápida absorción, acorde con los hallazgos de otros estudios (33-36), puesto que desde los primeros 15 a 30 minutos se observaron signos de envenenamiento tales como sialorrea, disnea y excitabilidad. El envenenamiento producido luego de la inyección del veneno por vía intraperitoneal fue mucho más rápido e intenso que por vía subcutánea y, además, se presentó hiperhidrosis, lagrimación y muerte; esta última ocurrió en 1-3 horas con $1 \mathrm{DL}_{50}$ por vía intraperitoneal. El veneno también es de rápida eliminación, puesto que en los ratones sobrevivientes los signos fueron desapareciendo después de las primeras 2 a 3 horas posinoculación.

Uno de los signos de envenenamiento sistémico escorpiónico es la hiperglicemia $(17,13,20,37)$. El veneno de $T$. pachyurus indujo esta alteración metabólica en los ratones a dosis bajas $\left(0,5 \mathrm{DL}_{50}\right)$, pero no cuando se inyectó $1 \mathrm{DL}_{50}$ por vía subcutánea, observación que se reprodujo al repetir el experimento y para la cual hasta ahora no tenemos una explicación objetiva. Además, es importante resaltar que este veneno no produjo aumento de amilasas séricas a dosis moderadas $\left(1 \mathrm{DL}_{50}\right)$ en ratones, efecto que tampoco se apreció en víctimas humanas picadas por esta especie en el departamento de Tolima, en el estudio clínicoepidemiológico prospectivo que se realizó recientemente (20). Sin embargo, hemos observado elevación de amilasas séricas en pacientes picados por escorpiones del mismo grupo como $T$. asthenes en Antioquia, en los cuales se ha demostrado por tomografía o ecografía abdominal, pancreatitis edematosa aguda o hemorrágica; esta complicación también se ha descrito en picaduras por otras especies de escorpiones de los géneros Tityus y Centruroides en Latinoamérica $(17,20)$.

Se demostró por electroforesis que hay una banda de proteínas muy densa por debajo de los $14 \mathrm{kd}$ (figura 2A), que podría corresponder a las neurotoxinas según lo encontrado en otros estudios (32,38-41). Aunque en el Western blot (figura 2B) estas proteínas fueron reconocidas por los tres antivenenos, el antiveneno de Venezuela no neutralizó el efecto letal del veneno en los experimentos de preincubación de venenoantiveneno. Esto permite enfatizar hallazgos similares de otros autores con venenos de serpientes, porque el hecho de que haya reconocimiento in vitro (en el Western blot) de los componentes de un veneno (homólogo e, incluso, heterólogo) por parte de un antiveneno, no significa que éste pueda neutralizar in vivo el efecto letal de ese veneno (42).

No obstante, el antiveneno de Venezuela prolongó el tiempo de supervivencia de los ratones en los experimentos de neutralización in vivo, mediante preincubación de veneno y antiveneno, y se logró hallar la $D E_{50}$ y la $D E_{100}$ para los antivenenos de México y Brasil $\left(D_{100}=225 \mu \mathrm{g}\right.$ de veneno $/ \mathrm{ml}$, es decir, que $1 \mathrm{mg}$ de veneno es neutralizado por 4,4 $\mathrm{ml}$ de antiveneno).

En diversos estudios se ha demostrado que existe reactividad cruzada entre un antiveneno monoespecífico o polivalente y los venenos de escorpiones de otras especies del mismo género o de géneros diferentes de la misma familia (1416). El hallazgo de una buena potencia neutralizante en los antivenenos de Brasil y México, producido este último contra especies del género Centruroides, podría explicarse por la conservación a lo largo de la evolución de la mayoría de los determinantes antigénicos de las toxinas de venenos de escorpiones de la familia Buthidae; se han encontrado similitudes en su estructura primaria y tridimensional (41). 


\section{Agradecimientos}

Al Instituto Bioclón S.A. de C.V., México, al Instituto Butantán, São Paulo, Brasil, y al Instituto de Biotecnología de la Universidad Central de Venezuela, por la donación de los antivenenos para el estudio. A la Universidad de Antioquia por la financiación de la investigación. A los compañeros del Grupo de Ofidismo/Escorpionismo de la Universidad de Antioquia. A los profesores Abel Díaz y Rafael Valderrama de la Facultad de Medicina de la Universidad de Antioquia.

\section{Referencias}

1. Lourenço WR, von Eickstedt VRD. Escorpiões de importância médica. En: Cardoso JLC et al., editores. Animais peconhentos no Brasil. Biología, clínica e terapêutica dos accidentes. $1^{\text {a }}$ edic. Sao Paulo: Sarvier; 2003. p.198-208.

2. Saldarriaga $\mathbf{M}$, Otero R. Los escorpiones: aspectos ecológicos, biológicos y toxinológicos. Medunab 2000;3: 17-23.

3. Flórez DE. Escorpiones de la familia Buthidae (Chelicerata: Scorpiones) de Colombia. Biota Colombiana 2001;2:25-30.

4. Lourenço WR. Synopsis de la faune de scorpions de Colombie, avec des considérations sur la systématique et la biogéographie des especès. Rev Suisse Zool 1997; 104:61-94.

5. Lourenço WR, Otero R. Tityus antioquensis sp. n., a new species of scorpion from the Department of Antioquia, Central Cordillera of Colombia (Scorpiones, Buthidae), with a checklist and key for the Colombian species of the genus. Ent Mitt Zool Mus Hamburg 1998; 12:297-307.

6. Lourenço WR. Synopsis of the Colombian species of Tityus Koch (Chelicerata, Scorpiones, Buthidae) with descriptions of three new species. J Nat Hist 2000;34: 449-61.

7. Brownell P, Polis G. Introduction. En: Brownell P, Polis $G$, editors. Scorpion biology and research. First edition. New York: Oxford University Press; 2001. p.3-12.

8. Dehesa-Dávila M, Alagón AC, Possani LD. Clinical toxicology of scorpions stings. En: Meier J, White J, editors. Handbook of clinical toxicology of animals venoms and poisons. First edition. Boca Ratón: CRC Press; 1995. p.221-38.

9. Hering S, De Azevedo-Marques M, Cupo P. Escorpionismo. En: Schvartsman S, editor. Plantas venenosas e animais peconhentos. Sâo Paulo: Sarvier; 1992. p.216-27.

10. Lucas SM, Meier J. Biology and distribution of scorpions of medical importance. En: Meier J, White J, edi- tors. Handbook of clinical toxicology of animal venoms and poisons. First edition. Boca Ratón: CRC Press; 1995. p.205-19.

11. Simard JM, Watt DD. Venoms and toxins. En: Polis G, Sissom W, editors. Life history. The biology of scorpions. Standford: Standford University Press; 1990. p. $414-43$

12. De Sousa L, Kiriakos D, Jiménez J, Michieli D, Rodríguez C, Mirabal J. et al. Accidente cerebrovascular isquémico por emponzoñamiento escorpiónico: observación clínica. Saber 1995;7:7-14.

13. Instituto Bioclón. Bases para el tratamiento en la intoxicación causada por mordedura de serpientes y picadura de alacrán. México: Instituto Bioclón; 1997. p.1-20.

14. Nishikawa AK, Caricati CP, Lima MLSR, Dos Santos MC, Kipnis TL, Eickstedt VRD, et al. Antigenic crossreactivity among the venoms from several species of Brazilian scorpions. Toxicon 1994;32:989-98.

15. Mancilla R, Olmos MA, Alagón A, González C, Possani LD, Paniagua JF. Reactividad cruzada de faboterápicos generados con venenos de alacranes de México y Venezuela. En: Memorias, Tercera Reunión de Expertos en Envenenamiento por Animales Ponzoñosos. Acapulco; 1999. p.60.

16. Estévez J, Alagón A, Paniagua J. Determinación de la reactividad cruzada del Alacramyn ${ }^{\circledR}$ hacia diferentes venenos de alacrán del género Centruroides spp. mediante la técnica de ELISA. En: Cuarta Reunión de Expertos en Envenenamiento por Animales Ponzoñosos. Cuernavaca; 2000. p.33-5.

17. Otero R, Uribe $\mathbf{F}$, Sierra $\mathbf{A}$. Envenenamiento escorpiónico en niños. Actual Pediatr FSFB 1998;8:8892.

18. Pineda D, Castellanos JA. Escorpionismo en Girardot. Hospital San Rafael, enero-junio de 1994. Tribuna Médica 1998;98:19-28.

19. Marinkelle CJ, Stahnke HL. Toxicological and clinical studies on Centruroides margaritatus (Gervais), a common scorpion in western Colombia. J Med Ent 1965; 2:197-9.

20. Otero R, Navío E, Céspedes FA, Núñez MJ, Lozano L, Moscoso E. R. et al. Scorpion envenomation in two regions of Colombia. Clinical, epidemiological and therapeutic aspects. Trans R Soc Trop Med Hyg (sometido para publicación).

21. Rosenblum JL, Hortin GL, Smith CH, Pashos GE, Landt M. Macroamylases: differences in activity against various-sized substrates. Clin Chem 1992;38: 1454-8.

22. Trinder P. Determination of blood glucose using an oxidase-peroxidase system with a non-carcinogenic chromogen. J Clin Path 1969;22:158-61. 
23. Smith HG, Bauer PJ. Light-induced permeability changes in sonicated bovine disks: Arsenazo III and flow system measurements. Biochemistry 1979;18: 5067-73.

24. Spector T. Refinement of the Coomassié Blue method of protein quantitation. A simple and linear spectrophotometric assay for 0.5 to $50 \mu \mathrm{g}$ of protein. Anal Biochem 1978;86:142-6.

25. Laemmli UK. Cleavage of structural proteins during the assembly of the head of bacteriophage $T_{4}$. Nature 1970;227:680-5.

26. Lomonte B, Rojas LG. Inmunología: manual de laboratorio. San José: Universidad de Costa Rica, Instituto Clodomiro Picado; 1996. p.37- 52.

27. Towbin H, Staehelin T, Gordon J. Electrophoretic transfer of proteins from polyacrylamide gels to nitrocellulose sheets: procedure and some applications. Proc Natl Acad Sci USA 1979;76:4350-4.

28. World Health Organization. Progress in the characterization of venoms and standardization of antivenoms. Geneva: WHO; 1981.

29. Gutiérrez JM, Rojas G, Lomonte B, Gené A, Chaves F. Evaluación de la capacidad neutralizante de los antivenenos en América. San José: Instituto Clodomiro Picado, Universidad de Costa Rica; 1990.

30. Otero R, Osorio RG, Saldarriaga MM, Lotero G, Villa NH. Boletín Toxinológico Toxinotas 2000;4:1-4.

31. Valderrama R. Envenenamiento por picadura de escorpiones. En: Otero R, Angel R, García M, editores. Primer Simposio Colombiano de Toxinología: toxinas y envenenamiento por animales, plantas y microorganismos. Medellín: Ecográficas Ltda; 1998. p.16978.

32. Céard B, De Lima ME, Bougis PE, Martin-Euclaire MF. Purification of the main $\beta$-toxin from Tityus serrulatus venom using high perfomance liquid chromatography. Toxicon 1992;30:105-10.

33. Gómez JP, Otero R, Núñez V, Saldarriaga MM, Díaz A, Velásquez MP. Aspectos toxinológicos, clínicos y epidemiológicos del envenenamiento producido por el escorpión Tityus furhmanni Kraepelin. Medunab 2002; 5:159-65.

34. Cunha-Melo JR, Toppa NH, Martins P, Colares CN, Castro YS, Freire-Maia L. Acute gastric mucosal injury induced by toxins from Tityus serrulatus scorpion venom: a novel experimental model in the rat. Toxicon $1991 ; 29: 1395-401$.

35. Otero R. Seroterapia antivenenosa. Ventajas del uso de antivenenos del tipo $\lg G, F\left(a b^{\prime}\right)_{2}$ o Fab en picaduras de escorpiones y mordeduras de serpientes. Pediatría 2002;37:8-16.

36. Revelo MP, Bambirra EA, Ferreira AP, Diniz CR, Chávez-Olórtegui C. Body distribution of Tityus serrulatus scorpion venom in mice and effects of scorpion antivenom. Toxicon 1996;34:1119-25.

37. Cupo P, Jurca M, Azevedo-Marques MM, Oliveira JSM, Hering SE. Severe scorpion envenenomation in Brazil. Clinical, laboratory and anatomopathological aspects. Rev Inst Med Trop Sao Paulo 1994;36:67-76.

38. Becerril B, Marangoni S, Possani LD. Toxins and genes isolated from scorpions of the genus Tityus. Toxicon 1997;35:821-35.

39. Becerril B, Corona M, Coronas FIV, Zamudio F, Calderón-Aranda ES, Fletcher PL et al. Toxic peptides and genes encoding toxin $\gamma$ of the Brazilian scorpions Tityus bahiensis and Tityus stigmurus. Biochem J 1996;313:753-60.

40. Batista CVF, Zamudio FZ, Lucas S, Fox JW, Frau A, Prestipino $G$ et al. Scorpion toxins from Tityus cambridgei that affect $\mathrm{Na}^{+}$-channels. Toxicon 2002;40: 557-62.

41. Possani LD, Merino E, Corona M, Bolívar F, Becerril B. Peptides and genes coding for scorpion toxins that affect ion-channels. Biochimie 2000;82:861-8.

42. Prieto da Silva A, Yamagushi I, Morais J, Higashi H, Raw I, Ho P, de Oliveira J. Cross reactivity of different specific Micrurus antivenom sera with homologous and heterologous snake venoms. Toxicon 2001;39:949-53. 